\title{
CLARA, A CLARIVIDENTE: O INSÓLITO FICCIONAL NA PERSONAGEM
}

\section{LAÍS GEROTTO DE FREITAS VALENTIM*}

Universidade Presbiteriana Mackenzie (UPM), Programa de Pós-Graduação em Letras (PPGL), São Paulo, SP, Brasil.

Recebido em: 17 dez. 2020. Aprovado em: 4 mar. 2021.

Como citar este artigo: VALENTIM, L. G. de F. Clara, a clarividente: o insólito ficcional na personagem. Cadernos de Pós-Graduação em Letras, v. 21, n. 1, p. 85-97, jan./abr. 2021. doi: 10.5935/cadernosletras. v21n1p85-97

\section{Resumo}

Este artigo objetiva analisar Clara, personagem do livro A casa dos espíritos (2017) da escritora chilena Isabel Allende para identificar os elementos insólitos que sustentam as suas ações. Para isso, apresentamos uma breve fundamentação sobre realismo mágico e real maravilhoso, utilizando como apoio teórico os estudos de Irlemar Chiampi (1980), Allicia Llarena (1996), Teodósio Fernandéz (2001), Diana Palaversich (2005) e a tese de doutorado de Daniele Zaratin (2019). O desenvolvimento da narrativa, bem como as ações da personagem

* E-mail: laisgfvalentim@yahoo.com.br

(D) https://orcid.org/0000-0002-4708-3128 
Clara são compreendidos no âmbito do referencial teórico que aponta a relevância das imagens insólitas como formas de ruptura com um entendimento de mundo preestabelecido.

\section{Palavras-chave}

Clara. Insólito ficcional. Realismo mágico e maravilhoso.

\section{INTRODUÇÃO}

O presente trabalho tem por objetivo analisar a personagem Clara, do romance A casa dos espíritos, da escritora chilena Isabel Allende (2017), e verificar como as perspectivas teóricas do realismo mágico e do real(ismo) maravilhoso manifestam-se no romance e definem os perfis da protagonista.

A personagem Clara apresenta traços sobrenaturais e insólitos, além de ser uma das protagonistas da narrativa e ter importância para ela. Sendo assim, faremos a análise utilizando o subcapítulo 2 "Lo real maravilloso de América y la literatura fantástica", do capítulo 3 "O realismo maravilloso" do livro teórico Teorías de lo fantástico, de David Roas (2001); o livro O realismo maravilhoso: forma e ideologia no romance hispano-americano, de Irlemar Chiampi (1980); e o capítulo 4 - "Secretos de família. Decifrando la sexualidad en La casa de los espíritus de Isabel Allende" - do livro De Macondo a $\mathrm{McOndo:} \mathrm{senderos} \mathrm{de} \mathrm{la} \mathrm{postmodernidad} \mathrm{latinoamericana,} \mathrm{de} \mathrm{Diana} \mathrm{Pala-}$ versich (2005), que orientam uma possibilidade de leitura das atitudes e ações da personagem, bem como os acontecimentos na obra. Não poderíamos também deixar de mencionar a relevância que tiveram o capítulo 1 - "O insólito ficcional no contexto hispano-americano" da tese Perspectivas do insólito ficcional: uma análise dos romances de Gioconda Belli e Maria Amparo Escandón, de Daniele Aparecida Pereira Zaratin (2019), e o artigo de Alicia Llarena (1996) "Lo real maravilloso americano: una propuesta de integración".

O livro A casa dos espíritos é de extrema relevância no mundo, visto que Isabel Allende (2017) tem grande reconhecimento internacional e foi seu primeiro trabalho, com o qual ficou conhecida e já por ele muito elogiada. 


\section{REALISMO MÁGICO E REAL(ISMO) MARAVILHOSO: O QUE SÃO?}

O realismo mágico é uma vertente estética europeia que apresenta características sobrenaturais e maravilhosas e pode vir a ser um desdobramento do fantástico, mas não necessariamente o é. Já o real(ismo) maravilhoso é uma vertente latino-americana a qual "preserva algo do humano, em sua essência. A extraordinariedade se constitui da frequência ou densidade com que os fatos ou os objetos exorbitam as leis físicas e as normas humanas" (CHIAMPI, 1980, p. 48).

Em sua segunda acepção, o maravilhoso difere radicalmente do humano: é tudo o que é produzido pela intervenção dos seres sobrenaturais. Aqui, já não se trata de grau de afastamento da ordem normal, mas da própria natureza dos fatos e objetos. Pertencem a outra esfera (não humana, não natural) e não têm explicação racional (CHIAMPI, 1980, p. 48).

Podemos observar, ainda, na seguinte passagem que há uma mescla, um diálogo entre ambas as acepções do real(ismo) maravilhoso:

Não sabemos qual dessas acepções é a original, mas ambas são valiosas para a compreensão das manifestações do maravilhoso no romance hispano-americano atual: enquanto, em alguns, os acontecimentos ou personagens são simplesmente extraordinários (acepção 1), como Los passos perdidos, outros incorporam o maravilhoso-sobrenatural, como Pedro Páramo (acepção 2). Outros, ainda, amalgamam o maravilhoso hiperbólico com o maravilhoso puro, como Hombres de maíz ou Cien años de soledad. Essas possibilidades lexicais do termo maravilhoso permitem, portanto, ótima especulação teórica sobre a forma discursiva do realismo maravilhoso, como a análise estilística da retórica construída para estabelecer as "passagens" de um significado a outro (CHIAMPI, 1980, p. 48-49, grifos da autora).

Essa denominação entre o real e a sua expressão literária é consequência da vanguarda dos anos 1920 e da ideia de que a América foi criada a partir das experiências dos jovens escritores latino-americanos. Há muitas razões para a América Latina ser portadora de intensa reivindicação social e cultural nesse sentido, como apreciar as diferenças e respeitá-las, e existem a erudição versus natureza e a razão versus espontaneidade. Vejamos:

87 
A pretensão de ver o mundo com novos olhos exigia olhar para algo como se tivesse acabado de surgir do nada - "como em um primeiro florescimento", segundo escreveu Bornes em um de seus textos ultraístas -, e nada mais adequado a esse respeito do que uma América jovem ou menina observada por um Ocidente que se dizia em decadência e se mostrava ávido por maravilhas, como evidenciado por uma arte que até então estendia seus domínios para o âmbito do irracional, para os mistérios do sonho e do subconsciente (FERNANDÉZ, 2001, p. 288, tradução nossa).'

Não há dúvida de que todo encontro é um convite à prática do rechaço ou reconhecimento, como exposto por Bakhtin, e entender esse modo de ser hispano-americano ou essa fração plural, rica, mestiça e mágica de sua realidade só seria possível se a América Latina deixasse de ser, aos olhos dos estrangeiros, um espaço cultural definido como "exótico", para adquirir os valores da verdade e da autenticidade. E isso é justamente o que queria Carpentier: o reconhecimento de algo tão primário e evidente como os elementos maraviIhosos e identificadores de sua realidade (LLARENA, 1996, p. 11, tradução nossa). ${ }^{2}$

O surrealismo pertence ao universo do realismo mágico que deu a Carpentier os direitos da magia e a necessidade da fé em seres e coisas superiores (sobrenaturais), e não só Carpentier, mas outros escritores também usavam o realismo mágico para explicar coisas que a ciência não conseguia:

Entendo que essa proposta não é menos arraigada do que a outra, a qual desde já prefiro: o fantástico fala de zonas escuras e incertas que estão mais para além do familiar e do conhecido. 0 movimento dessas fronteiras não implica o seu desaparecimento: os avanços científicos não implicam o fim dos mistérios, assim como a evolução da teologia não anulou o insólito dos milagres, tampouco a psicanálise (ao contrário do que dizia Todorov) colocou fim ao horror dos pesadelos. A literatura fantástica do século XX explorou territórios

1 La pretensión de ver el mundo con ojos nuevos exigió que se viese como si acabase de surgir de la nada - "como en una primicial floración”, según escribió Bornes en una de sus proclamas ultraístas y nada más adecuado al respecto que una América joven o niña observada por un Occidente que se decía en decadencia y se mostraba ávido de maravilla, como prueba un arte que entonces extendía sus dominios al ámbito de lo irracional, a los misterios del sueno y del subconsciente.

2 No cabe duda de que todo encuentro invita a practicar un rechazo o un reconocimiento, tal como expuso Bajtín, y que entender ese modo de ser hispanoamericano, o esa fracción plural, rica, mestiza y mágica de su realidad, sólo sería posible si América Latina deja de ser, para ojos exteriores, un espacio cultural definido como "exótico", para adquirir los valores de la verdad y de la autenticidad. Y eso es justamente lo que intentaba Carpentier: el reconocimiento de algo tan primario y evidente como los elementos maravillosos e identificadores de su realidad. 
que a razão e a ciência da época não conseguiam explicar (FERNANDÉZ, 2001, p. 295, tradução nossa). ${ }^{3}$

Observa-se, em diferentes perspectivas estéticas, a presença do insólito ficcional, um acontecimento estranho, incomum que causa surpresa ou estranhamento no leitor, narrador ou personagem. Como afirma Zaratin (2019, p. 23):

[...] o insólito funda-se na ocorrência de um episódio que rompe as expectativas preestabelecidas pelo leitor acerca da realidade ficcional em contraposição à sua realidade empírica, o que pode causar, dependendo da vertente do insólito apresentada, assombro, maravilhamento, estranhamento, pânico, horror ou a sua aceitação apenas.

Ocorre, no insólito, a ambiguidade, a incerteza diante desse acontecimento por meio da materialidade do texto e da visão do leitor (elemento extralinguístico/extratextual). O insólito é o evento metaempírico que desencadeia, ou não, o fantástico. A partir da década de 1950, surgem escritores latino-americanos cuja escrita se vale desse insólito ficcional: o estranhamento e o encantamento; e isso acontece porque eles se valorizam e passam a valorizar a heterogeneidade que os diferencia dos europeus. Para os estudos literários, esse tema do insólito é algo recente ainda e busca compreender as distintas vertentes do sobrenatural. Sendo assim, esses autores buscaram certa autonomia e procuraram fazer uma literatura "de cunho mais imaginativo, de caráter menos mimético e mais plural, cujas vertentes dialogavam diretamente com as distintas facetas do insólito ficcional" (ZARATIN, 2019, p. 30).

Após esse período, da década de 1950 até a de 1970, temos o chamado “boom latino-americano" com a difusão de jovens escritores latino-americanos tendo sucesso na Europa e no mundo, e o “pós-boom” na década de 1980, no qual surge uma geração de mulheres muito boas na literatura (não que antes não existissem, mas é que, a partir desse período, elas passam a ser notadas e valorizadas), e, entre elas, destaca-se Isabel Allende, a qual, segundo Zaratin (2019, p. 46), apresenta “o poder da palavra, o passado-memória e dá voz

3 Entiendo que esa propuesta no es menos arriesgada que esta otra, que desde luego prefiero: lo fantástico habla de las zonas oscuras e inciertas que están más allá de lo familiar y lo conocido. El movimiento de esas fronteras no implica su desaparición: los avances científicos no terminan con los misterios, como el desarrollo de la teología no anuló lo insólito de los milagros, ni el psicoanálisis (contra lo que aparentaba creer Todorov) ha puesto fin al horror de las pesadillas. La literatura fantástica del siglo XIX habló de territorios que la razón y la ciencia de la época no alcanzaban a explicar. 
feminina às suas criações, em especial à personagem Clara, de $A$ casa dos espíritos". O sucesso de Isabel e das demais mulheres não é só por conta da temática, mas também por conta da maneira de narrar, porque há nisso um “deslocamento da personagem masculina para a feminina, possibilitando a inserção de sua voz num universo que é dominado historicamente por homens" e, sendo assim, "a partir de uma dupla perspectiva feminina: a da narradora e a da personagem feminina” (ZARATIN, 2019, p. 48).

Percebemos que Clara questiona o valor patriarcal ao tomar para si o protagonismo - não nos esqueçamos do papel fundamental que assume aqui a ditadura chilena em 1973, a qual culminou na derrocada de Salvador Allende, primo de Isabel, do poder para a instauração do regime militar e na morte dele. Embora Palaversich (2005, p. 71, tradução nossa) afirme:

A meu ver, A casa dos espíritos não é um texto feminista - que outorga a suas personagens femininas o papel de serem verdadeiras agentes de mudança -, seria mais um texto feminino e conservador cuja voz autoral, assim como suas personagens principais, permanece presa aos valores tradicionais e à ideologia heterossexual. ${ }^{4}$

Pode até "não ser um texto feminista, apenas com uma voz feminina presa dentro dos valores patriarcais” (PALAVERSICH, 2005, p. 71, tradução nossa), mas Clara assume um protagonismo marcante dentro do livro e chama a atenção nele. Isabel e as demais escritoras latino-americanas do "pós-boom" retratam em suas obras o insólito ficcional e o realismo mágico, os quais estão imersos na realidade dessas escritoras - realidade da qual são fruto e fazem parte, e podemos dizer que o livro A casa dos espíritos dialoga com essas duas teorias: o realismo mágico e o real maravilhoso.

\section{CLARA, A INSÓLITA PERSONAGEM CLARIVIDENTE}

Clara faz parte da segunda geração de mulheres da família Del Valle-Trueba; é filha de Nívea, mãe de Branca e avó de Alba. Tem poderes sobrenaturais

\footnotetext{
4 A mi ver, La casa do los espíritus no es un texto feminista - que outorga a sus personajes femininos el papel de ser verdaderos agentes de cambio - sino más bien un texto feminino y conservador cuya voz autoral, como también la de sus personajes principales, permanece atrapada dentro de los confines de los valores tradicionales y la ideología heterosexual.
} 
que a família muitas vezes não entende ou não acredita neles, dando pouca importância a isso.

Clara é uma personagem histórica, marcante, peculiar devido à questão do sobrenatural enraizada nela e inesquecível para o leitor. Está sempre pronta a ajudar os outros e vive no mundo dela. Vive quase um mundo à parte de sua casa e família, mas está imersa nele. Todos os acontecimentos nos quais se envolve possuem marcas do insólito, que possuem sentidos e casualidades internos. $\mathrm{O}$ tipo de narração também contribui para que o leitor se aproxime e veja os fatos como eles são: há uma mescla de narração em primeira pessoa - a qual permite uma aproximação com o leitor - e narração em terceira pessoa - a qual dá veracidade à narrativa.

Partindo desse panorama, vamos analisar a seguir alguns excertos do livro. O primeiro trata-se de quando há a menção de que Clara consegue mexer os objetos, no caso o saleiro, sem tocá-los:

Os poderes mentais de Clara não perturbavam ninguém e não provocavam maiores transtornos; manifestavam-se quase sempre em assuntos de pouca importância e na estrita intimidade do lar. Algumas vezes, à hora da refeição, quando estavam todos reunidos na grande sala de jantar da casa, sentados em absoluta ordem de autoridade e poder, o saleiro começava a vibrar e logo se deslocava sobre a mesa, contornando copos e pratos, sem mediação de qualquer fonte de energia conhecida nem truque de ilusionismo (ALLENDE, 2017, p. 16).

Fica claro que há um elemento insólito aqui, e, sendo Clara uma personagem com poderes mágicos, o texto, nesse momento, aproxima-se das características do real maravilhoso:

Um romance tão ancorado no realismo tradicional como Doña Bárbara apresenta personagens dotados de poderes mágicos, como a própria protagonista, sem que tal predicação seja assimilada pelo relato. Se neste caso o elemento mágico não chega a contaminar o texto como um todo, em romances como $\mathrm{El}$ reino de este mundo ou Cien años de soledad, os componentes atributivos de Mackandal ou Melquíades são absorvidos pela narrativa, mas, ainda assim quando os acontecimentos envolvem a prática mágica, a espécie "magia" subsuma-se à categoria do maravilhoso (CHAMPI, 1980, p. 47, grifos da autora).

Assim como Melquíades e Mackandal, Clara absorve os componentes da narrativa envolvendo-os na magia e "contaminando" não só o texto, como 
também as demais personagens - os eventos ocorridos com ela passam a ser normais para todos e para o leitor, inclusive. São eventos normalizados.

Em outra passagem, podemos ver que Clara invoca os seus poderes sobrenaturais de prever as coisas e fazer adivinhações; é possível perceber a sensibilidade dela com relação ao sexto sentido e às premonições:

[...] a própria Clara invocara inutilmente seus dotes de vidente. [...] Não a impressionaram as casas de tijolo, a escola e a abundância de comida, porque sua capacidade de ver o invisível detectou o receio, o medo e o rancor dos trabaIhadores, e o imperceptível rumor que se calava quando virava o rosto, que the permitiram adivinhar algumas coisas sobre o caráter e o passado de seu marido (ALLENDE, 2017, p. 117).

É possível observar que os seus poderes, inclusive os de vidente, dependem de duas coisas - uma força empírica e racional e a outra metaempírica e irracional:

0 acontecimento insólito, privado de qualquer probabilidade interna (patente, mas sem causa), superpõe duas probabilidades externas, uma racional e empírica (lei física, sonho, delírio, ilusão visual) e outra irracional e meta-empírica (mitologia, teologia, milagres, prodígios, ocultismo) (CHIAMPI, 1980, p. 56).

A personagem, ao ter suas vidências, tem seus delírios e ilusões visuais atrelados aos prodígios e ao ocultismo presentes nela. Foi assim também quando previu uma iminente morte na família - a qual veio a saber mais tarde que seria a da irmã Rosa -, que a deixou inquieta por dias e muda por anos após o acontecimento.

O trecho que mais surpreende o leitor, no entanto, é quando ela narra sonhar com a cabeça da mãe e faz de tudo para trazê-la de volta. Seus pais haviam morrido em um acidente de carro, e a cabeça de Nívea, mãe de Clara, é arremessada para fora do carro. Ninguém conta o incidente a Clara, que está grávida, porém ela adivinha que algo estranho acontece, prevê onde está a cabeça da mãe e, com a ajuda da cunhada, Férula, trá-la de volta. Trueba diz à irmã:

- Meus sogros morreram num acidente - informou-a brevemente. - Não quero que Clara saiba antes do parto. Temos de fazer um muro de censura à sua volta, nem jornais, nem rádio, nem visitas, nada! Vigie os empregados para que ninguém lhe diga nada. 
Suas boas intenções, contudo, anularam-se pela força das premonições de Clara (ALLENDE, 2017, p. 132).

E continua, aqui, a narração exatamente quando há o resgate da cabeça e as consequências dessa ação:

- Senhor, faça-me a gentileza de entrar ali e pegar uma cabeça de senhora que vai encontrar - pediu ao motorista.

Ele se arrastou sob os espinhos e encontrou a cabeça de Nívea, que parecia um melão solitário. Pegou-a pelo cabelo e saiu com ela, engatinhando. Enquanto o homem vomitava, apoiado numa árvore próxima, Férula e Clara limparam Nívea da terra e dos seixos que havia em suas orelhas, seu nariz e sua boca, e ajeitaram-Ihe o cabelo, que se despenteara um pouco, mas não the puderam fechar os olhos. Envolveram-na num xale e regressaram ao coche (ALLENDE, 2017, p. 135-136).

“Chegaram justamente a tempo de acomodar a mãe em sua cama. [...] Antes que chegassem o médico e a parteira, ocultou sob a cama a cabeça de Nívea, a fim de evitar explicações embaraçosas" (ALLENDE, 2017, p. 136).

Consideramos esse o fato mais insólito de todo o livro - todos são, mas o mais incomum e improvável acontece aqui. Embora estranho, o acontecimento é aceito pelo leitor, faz parte da realidade da personagem, e Férula o aceita naturalmente também. Não há dúvida de que isso aconteceu de fato. Vejamos o que diz Irlemar Chiampi (1980, p. 59):

Ao contrário da "poética da incerteza", calculada para obter o estranhamento do leitor, o realismo maravilhoso desaloja qualquer efeito emotivo de calafrio, medo ou terror sobre o evento insólito. No seu lugar, coloca o encantamento como um efeito discursivo pertinente à interpretação não-antitética dos componentes diegéticos. 0 insólito, em óptica racional, deixa de ser o "outro lado", o desconhecido, para incorporar-se ao real: a maravilha é(está) (n)a realidade. Os objetos, seres ou eventos que no fantástico exigem a projeção lúdica de duas probabilidades externas e inatingiveis de explicação, são no realismo maravilhoso destituídos de mistério, não duvidosos quanto ao universo de sentido a que pertencem. Isto é, possuem probabilidade interna, tem causalidade no próprio âmbito da diegése e não apelam, portanto, à atividade de deciframento do leitor.

[...]

Esta noção segue o mesmo princípio utilizado para definir o modo de percepção do fantástico: o realismo maravilhoso se qualifica pela relação entre o 
efeito de encantamento (o discurso) e o relato. A diferença introduzida é que, em vez de assinalar-se a constituição não-antitética dos acontecimentos como o segundo termo da relação, preferimos designá-lo como "componentes diegéticos", a fim de ampliar a correlação subsequente entre o aspecto semântico (fusão natureza/sobrenatureza) e o aspecto sintático (causalidade interna) do texto narrativo.

Não podemos negar que há um encantamento do leitor com Clara, e a passagem da cabeça, mesmo sendo estranha, é aceita naturalmente também por conta do relato que não causa medo no leitor.

Veremos dois excertos nos quais Clara começa a se preparar para a morte - até isso ela é capaz de prever - e faz a neta, Alba, entender que estarão ligadas para sempre além da vida:

Clara morreu no dia em que Alba fez sete anos. 0 primeiro anúncio de sua morte só foi perceptível para ela. Então começou a fazer secretas disposições para partir. Com absoluta discrição distribuiu sua roupa pelas empregadas e pelos muitos protegidos que sempre tivera, deixando-se apenas o indispensável. Organizou seus papéis, recolhendo dos cantos esquecidos seus cadernos de anotar a vida.

[...]

Alba entrou nesse momento e viu seu avô reduzido à sua altura, aproximou-se, ficou olhando surpresa para ele e abraçou-o quando the viu as lágrimas. Pelo pranto do velho a menina tomou conhecimento da notícia. Ela foi a única pessoa da casa a não perder a calma, devido a seus treinamentos para suportar a dor e ao fato de sua avó lhe ter explicado tantas vezes as circunstâncias e os trabalhos da morte.

- Tal como no momento de vir ao mundo, ao morrer temos medo do desconhecido. Mas o medo é algo interior, que nada tem a ver com a realidade. Morrer é como nascer: apenas uma mudança - tinha lhe dito Clara.

Acrescentara que, se era capaz de se comunicar sem dificuldades com as almas do Além, estava totalmente convicta de que, depois, poderia fazê-lo com as almas do Aquém, de modo que, em vez de choramingar quando o momento chegasse, queria que estivesse tranquila, porque no seu caso a morte não seria uma separação, mas uma forma de estarem mais unidas. Alba compreendeu perfeitamente (ALLENDE, 2017, p. 311-313).

Duas coisas merecem ser mencionadas aqui: a sua generosidade para com as pessoas de classe baixa e seus empregados, por quem tinha afeição e carinho 
porque os ajudava sempre que podia. Clara gostava de fazer caridade, conseguindo até mesmo a amizade de algumas pessoas que não eram da mesma condição social que a dela. Era uma unanimidade dentro da narrativa - todos gostavam dela e grande parte aceitava o seu jeito de ser com todos os eventos à sua volta. Vejamos:

O encantamento do realismo maravilhoso é conceitual; é sério e revisionista da perda da imagem do mundo que o fantástico atestava. Isto talvez queira dizer que o jogo se radicalizou (Borges fala da fé poética que substitui a dúvida suspendida). Em todo caso, ao leitor desamparado e aterrorizado pela fuga do sentido no fantástico, é restituído o sentido: a fé na transcendência de um estado extranatural, nas leis meta-empíricas (CHIAMPI, 1980, p. 61).

Há, ainda, uma passagem no começo do livro na qual Férula morre, aparece para todos na casa, porém os ignora, vai ao encontro de Clara e dá-lhe um beijo:

Logo em seguida ouviram o tilintar das chaves, e quase imediatamente abriu-se a porta, aparecendo Férula, silenciosa e com expressão distante, ao mesmo tempo em que Nana entrava pela porta da cozinha, com a travessa de salada. Esteban Trueba, a faca e o garfo de trinchar no ar, ficou paralisado pela surpresa, e os três meninos gritaram, tia Férula!, quase em uníssono. Blanca levantou-se para ir a seu encontro, mas Clara, que se sentava a seu lado, estendeu a mão e segurou-a por um braço. Na realidade, Clara foi a única que percebeu, ao primeiro olhar, o que estava ocorrendo, devido à sua grande familiaridade com os assuntos sobrenaturais, apesar de nada no aspecto de sua cunhada denunciar seu verdadeiro estado. [...] Férula aproximou-se dela, pôs as mãos em seus ombros e deu-lhe um breve beijo na testa. [...]

- Férula morreu - anunciou (ALLENDE, 2017, p. 162).

É o que acontece com Clara: há a fé no sobrenatural - o que é normalizado, e não há medo nem dúvidas quanto a isso. Mesmo as demais personagens normalizam esse acontecimento. Ressaltamos, também, que ela prova a sua força em vários momentos, inclusive quando transmite à neta, uma criança ainda, tranquilidade e serenidade ao se preparar para morrer e pedindo para que ela não sofra, pois estarão ligadas para sempre. Clara, mesmo depois de morta, aparece para Alba a fim de aconselhá-la e guiá-la em seus passos. 


\section{CONCLUSÕES}

Clara é uma personagem cativante, marcante, histórica, e o leitor acaba incorporando os eventos que acontecem com ela como naturais devido à presença naturalizada do insólito ficcional: surgem então um encantamento e uma identificação. Os acontecimentos da vida de Clara - os seus poderes - em alguns momentos são divertidos.

A personagem é unanimidade mesmo entre as demais do livro por ser generosa, compreensiva e boa. Mesmo vivendo em um mundo à parte da realidade das demais, todas a compreendem e normalizam os acontecimentos insólitos e sobrenaturais dela, assim como o leitor que a aceita como tal. Não podemos deixar de dizer que há um encantamento com os poderes sobrenaturais da personagem que leva a uma normalidade dentro daquela existência: aquilo tudo faz sentido para Clara e para a narrativa.

Alguns aspectos do realismo mágico e do real maravilhoso desafiam o leitor a compreender as diferentes dimensões de Clara, um personagem cativante. Isabel Allende, nesse romance, consegue envolver os seus leitores e instigar a sua imaginação, bem como retrata a realidade de seu país de forma singular por meio de sua personagem - ainda que ela viva em um mundo à parte dos demais - que possui uma força que encanta a todos. O romance estando imerso na ditadura chilena e nos valores patriarcais faz com que se transforme em uma imagem de resistência simbólica das vozes quase sempre silenciadas.

\section{Clara, the clairvoyant: the fictional unusual in her}

\section{Abstract}

This article aims to analyze Clara, a fictional character from the book The house of spirits (2017), by Chilean writer Isabel Allende, to identify the unusual elements that support her actions. For this, we present a brief foundation on magical realism and wonderful real, using as theoretical support the studies of Irlemar Chiampi (1980), Allicia Llarena (1996), Teodósio Fernández (2001), Diana Palaversich (2005), and the doctoral thesis of Daniele Zaratin (2019). The development of the narrative and Clara's actions are understood within the theoretical framework that points to the relevance of unusual images as forms of rupture with a pre-established understanding of the world. 


\section{Keywords}

Clara. Fictional unusual. Magical realism and marvellous real.

\section{REFERÊNCIAS}

ALLENDE, I. A casa dos espíritos. Tradução Carlos Martins Pereira. São Paulo: Folha de S.Paulo, 2017. (Coleção Folha Mulheres na Literatura, v. 3).

CHIAMPI, I. O realismo maravilhoso: forma e ideologia no romance hispano-americano. São Paulo: Perspectiva, 1980.

FERNANDÉZ, T. O realismo maravilloso. In: ROAS, D. (comp.). Teorías de lo fantástico. Madrid: Arco Libros, 2001. p. 283-297.

LLARENA, A. Lo real maravilloso americano: una propuesta de integración. Espejo de paciencia, Las Palmas de Gran Canaria, n. 1, p. 20-30, 1996. Disponível em: http:// www.aliciallarena.com/downloads/lorealmaravillosoamericano.unapropuestadeinteg. pdf. Acesso em: 17 nov. 2020.

PALAVERSICH, D. Secretos de família. Decifrando la sexualidad en La casa de los espíritus de Isabel Allende. In: PALAVERSICH, D. De Macondo a McOndo: senderos de la postmodernidad latinoamericana. Ciudad de México: Plaza y Valdés, 2005. p. 61-71.

ZARATIN, D. A. P. Perspectivas do insólito ficcional: uma análise dos romances de Gioconda Belli e Maria Amparo Escandón. 2019. 230 f. Tese (Doutorado em Letras) Universidade Presbiteriana Mackenzie, São Paulo, 2019. 